\title{
Uterine Cervix Metastasis of Myxopapillary Ependymoma Originated from the Spinal Cord
}

\author{
Kadir Güzin ${ }^{1}$, Halenur Bozdağ ${ }^{1}$, Abdullah Aydın², Sadık Şahin, Şeyma Özkanlı² \\ ${ }^{1}$ Department of Obstetrics and Gynecology, İstanbul Medeniyet University Göztepe Training and Research Hospital, İstanbul, Turkey \\ ${ }^{2}$ Department of Pathology, İstanbul Medeniyet University Faculty of Medicine, İstanbul, Turkey \\ ${ }^{3}$ Departmenf of Obstetrics and Gynecology, Zeynep Kamil Training and Research Hospital, İstanbul, Turkey
}

Background: Myxopapillary ependymomas are well differentiated low-grade tumors which have been documented to local or distant metastasis. In the literature, this is a unique case of myxopapillary ependymoma with metastasis to the uterine cervix. Here, we present a rare case of extra neural metastasis of spinal ependymoma that developed over a long period.

Case Report: A 34-year-old woman was referred to our hospital for pelvic mass. A mass $(110 \times 100 \mathrm{~mm})$ localized between the sacrococcygeal region and the uterus was detected by magnetic resonance imaging. In 2004, she had been operated upon for myxopapillary ependymoma seated in the sacrococcygeal region for the first time. She underwent tumor resection eight times due to the recurrence of spinal tumor in the same region in nine years. Under the diagnosis of uterine neoplasm, we carried out radical hysterectomy, omentectomy and pelvic lymphadenectomy as the surgical procedure. The pathological findings were reported as myxopapillary ependymoma. Immunohistochemically, the myxopapillary ependymal cells showed strong positivity for glial fibrillary acidic protein, whereas they were negative for low molecular weight cytokeratin. The Ki-67 labeling index was about 2-3\%. The patient had an uneventful postoperative period. She has remained free of symptoms in the year since surgery.

Conclusion: Extra-spinal myxopapillary ependymoma is very rare, but it must be considered in the differential diagnosis of pelvic mass lesions.

Keywords: Ependymoma, spinal cord tumor, uterine cervix
Ependymomas are neuro-epithelial tumors that arise from ependymal cells. Myxopapillary ependymoma (MPE) is a welldifferentiated, low-grade and infrequent subtype of ependymal tumors $(1,2)$. The prognosis for MPE is better than the other types of ependymomas, although MPE tends to recur and exhibits local infiltration. Tumor recurrences usually occur in the same region from which the primary tumor originated. However, local or distant metastasis of MPE has been documented in the literature (3-5). Here, we report a unique case of MPE in the sacrococcygeal region with metastasis to the uterine cervix.

\section{CASE PRESENTATION}

A 34-year-old woman, gravidity IV, para IV, was referred to the University Hospital with the diagnosis of a pelvic mass. She first exhibited lower back pain that developed when she was 23-years-old and had continued during a pregnancy in that year. Assessment after the delivery included a neurological examination and radiological imaging. Computed tomography $(\mathrm{CT})$ and magnetic resonance imaging (MRI) showed

This study was presented at the 10 ${ }^{\text {th }}$ Turkish-German Gynecology Congress, 30 April - 4 May 2014, Antalya, Turkey.

Address for Correspondence: Dr. Kadir Güzin, Department of Obstetrics and Gynecology, İstanbul Medeniyet University Göztepe Training and Research Hospital, İstanbul, Turkey

Phone: +90 5425231577 e-mail: kguzin@gmail.com

Received: 13 January 2015 Accepted: 12 May 2015 •DOI: 10.5152/balkanmedj.2015.151101

Available at www.balkanmedicaljournal.org 

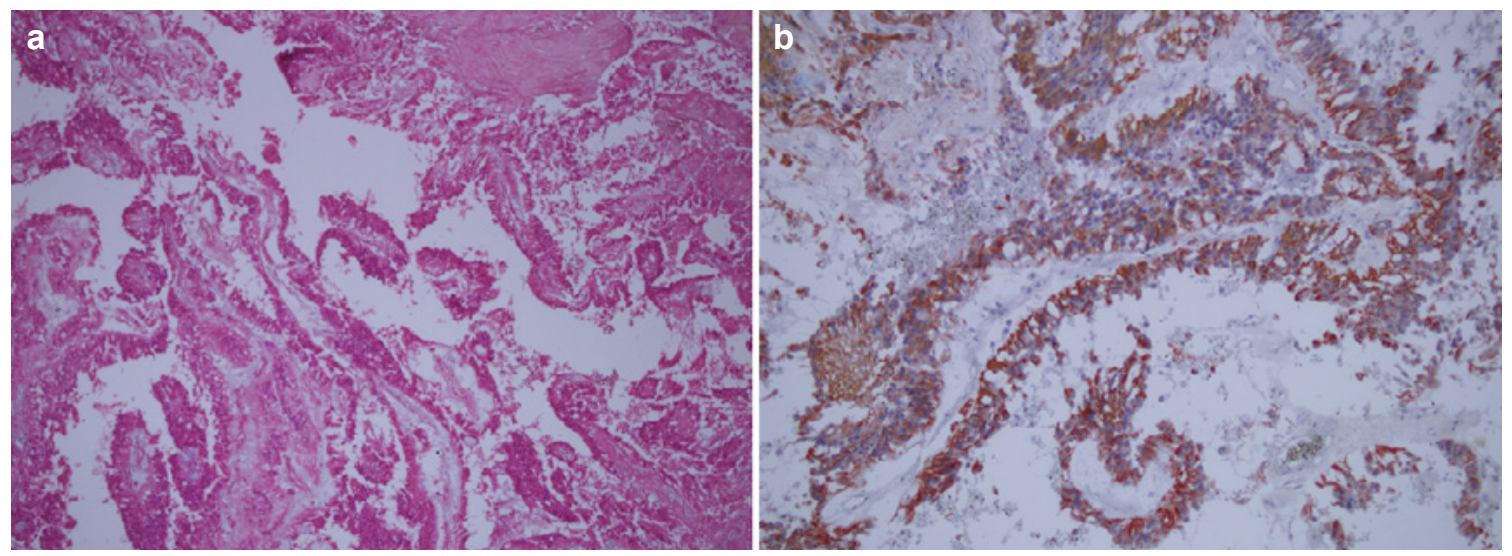

FIG. 1. a, b. The histopathological images belonging to a previous sacral tumor. The myxoid area positioned between small vessels, around which small tumor cells aggregates are shown (H\&Ex4) (a). The tumor cells are positive for glial fibrillary acidic protein (GFAPx20) (b). MRI images for the case (c).

a tumor in the lumbosacral region. The tumor was surgically resected in 2004 (her first surgery). The pathological diagnosis was myxopapillary ependymoma (Figure 1a, b). After the surgery, she suffered from a loss of sensation in the anal and genital regions, as well as anal sphincter disturbances.

She suffered from leg pain and weakness of the extremities in 2008 with the second pregnancy. She underwent tumor resection due to local recurrence, which was performed by an anteroposterior approach (her second surgery). Because of the persistence of symptoms and tumor recurrence in the same region, she underwent additional tumor resections (her third and fourth surgeries). The MRI was performed for control of the surgical site, and showed a new tumor that was localized at a higher level than that site in which the previous tumor was excised; therefore, the patient underwent an additional surgical resection (her fifth surgery). The patient underwent six surgeries because of the recurrence of the tumor in the same region and severe limb and sacral pain. The patient's quality of life deteriorated with an additional recurrence of the local tumor and the associated impairment of function. Thus, a team of radiologists performed image-guided stereotactic radio-surgery using the CyberKnife robotic radio surgery system (Accuray, USA) three months after the sixth surgery. Chemotherapy was administered for four months in addition to radiation therapy.

The patient was referred to our hospital in 2013 for evaluation of a pelvic mass, with the reported sensation of abdominal fullness and pelvic pain. Pelvic examination revealed a mass that fully filled the pelvis and depressed the urinary bladder. Trans-abdominal ultrasonography (General Electric LOGIQ 5 , USA) showed an enormous heterogeneous mass in the pelvis. The MRI (General Electric Medical Systems, EXCITEHD $8 \mathrm{CH} 1.5 \mathrm{~T}$, USA) confirmed a tumor $(110 \times 100 \mathrm{~mm})$ that was localized between the sacrococcygeal region and the uterus (Figure 2a-c). Also, a tumoral involvement of sacro- coccygeal region was detected by MRI screening (Figure 2d) large part of the tumor was located in the left uterine adnexa leading to the dilation of the left ureter due to a compression effect of the mass. Based on the initial diagnosis of uterine neoplasm, a laparotomy was performed. During surgery, we identified a large, solid pelvic mass seated in the uterine cervix, measuring approximately $11 \times 10 \mathrm{~cm}$ and extending to the sacrum (Figure 3a). We performed a radical hysterectomy and pelvic lymphadenectomy. MPE was identified on pathology (Figure 3b). Macroscopically, the lobulated tumor was hemorrhagic and was dark red to brown. The uterus was infiltrated by the tumor and severely atrophied, and the tumor circumferentially surrounded the cervix. Immunohistochemically, the myxopapillary ependymal cells showed a strong positivity for glial fibrillary acidic protein, whereas they were negative for the low molecular weight anti-cytokeratin (CAM5.2). The Ki-67 labelling index was approximately $2-3 \%$. The patient had an uneventful post-operative period. Despite the absence of strict therapeutic strategies within the accepted guidelines, she received radiotherapy with combined chemotherapy. She remained symptom-free for one year after the surgery. Local recurrence or metastasis has not been detected during the one year follow-up. Written informed consent was obtained from the patient for the publication of this case report and any accompanying images.

\section{DISCUSSION}

Ependymal tumors have been divided into subgroups based on the World Health Organization (WHO) 2007 classification system as subependymoma (WHO grade I), MPE (WHO grade I), ependymoma (WHO grade II) and anaplastic epen- 


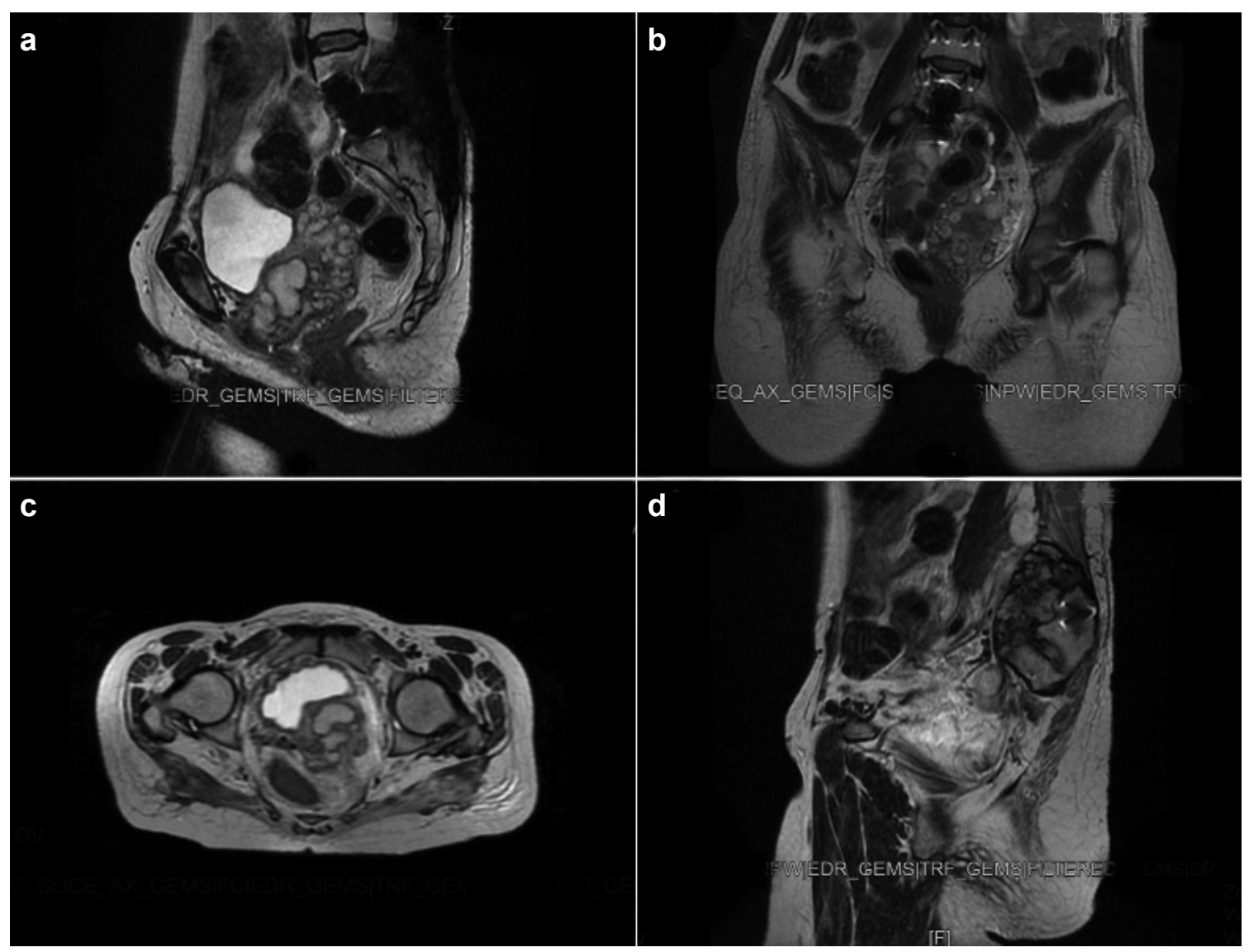

FIG. 2. a-d. The sagittal T2-weighted image of the pelvis shows a mass near the coccyx (a), the coronal T2-weighted image reveals a multilobulated mass in the pelvic area (b). The axial contrast enhanced image shows a huge mass extending to pelvic area from the sacral region (c). The sagittal T2-weighted image demonstrated marked tumoral involvement of sacrococcygeal region (d).
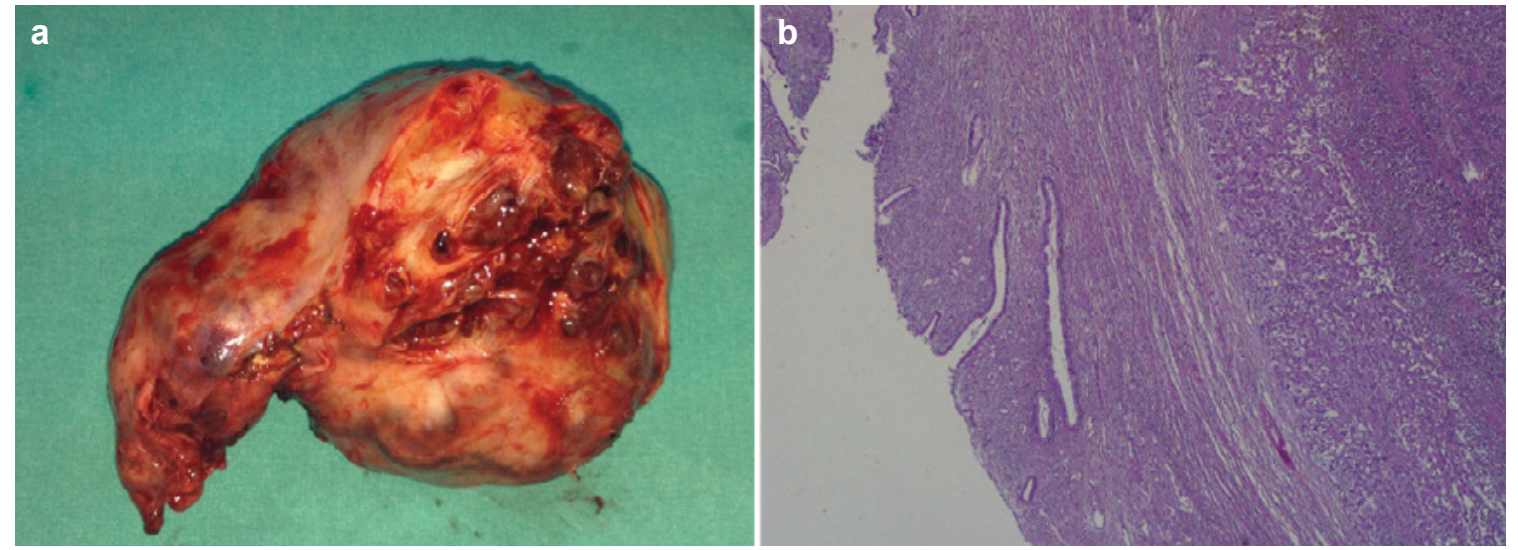

FIG. 3. a, b. Photograph of the sectioned gross specimen showing a dark red to brown lobulated tumor seated in the uterine cervix with uterus and adnexa (a). A micrograph of current MPE. Ependymomas are composed of cells with regular, round to oval nuclei with a variably dense fibrillary background $(x 200)(b)$.

dymoma (WHO grade III) (6). The most common form of ependymoma in the lumbar spine is the myxopapillary subtype, accounting for $13 \%$ of all spinal ependymomas and $90 \%$ of all tumors in the conus medullaris. These tumors have a tendency to affect younger individuals (mean age, 36.4 years). Clinically, the most common finding is back pain due to nerve root compression, which occurs in $70-80 \%$ of patients. Other commonly reported symptoms include sensory and motor neuro- 
logical abnormalities (50-70\%), weakness (24-36.8\%) and sphincter dysfunction $(21.1-24 \%)(1,2)$. Histologically, both cellular pleomorphism and mitosis are quite rare, even after metastasis has occurred. Likewise, the tumor in our patient did not have the morphology typical of malignancy, such as mitosis or necrosis. The Ki-67 labelling indices of the initial and recurrent tumors were reported as $14.2 \%$ and $3.1 \%$, respectively (7). Our patient's tumor had a low Ki-67 labelling index of $2-3 \%$, which was reported as grade 1 despite having a high recurrence rate and extra-neuronal metastasis (8). The cornerstone for the treatment of MPE is early diagnosis and early surgical excision of the tumor. The total tumor resection rate of spinal ependymomas is approximately $70 \%$ and the reported tumor recurrence rates vary between different studies $(1,2)$. Piecemeal, total or subtotal surgical removal of the tumor affects the recurrence rate (1). Strict therapeutic strategies that were accepted by guidelines are lacking, but craniospinal irradiation is recommended for metastatic disease, and chemotherapy is not suggested as a primary treatment in cases with residual tumor (9).

There are reports of ependymomas that metastasize outside of the central nervous system $(4,5)$. The most likely pathways for the extra-neural metastasis of ependymal tumors could include both surgical manipulation in previous operations and dissemination via the bloodstream and/or the lymphatic system. Ependymomas usually develop from neuroectodermal tissues, and these tumors rarely arise from pelvic structures such as the ovary, uterosacral ligament and broad ligament $(3,10)$.

In conclusion, we presented a rare case of extra-neural metastasis of spinal ependymoma that developed over a long period. This is a unique case of MPE metastasis to the uterine cervix from a tumor in the sacrococcygeal region. Although extra-spinal MPE is very rare, it must be considered in the differential diagnosis of pelvic mass lesions. Furthermore, long-term postoperative follow-up should include the evaluation for metastasis to both near and distant organs as well as local recurrence.

\section{Ethics Committee Approval: N/A.}

Informed Consent: Written informed consent was obtained from the patient's parent who participated in this case.
Peer-review: Externally peer-reviewed.

Author contributions: Concept - K.G.; Design - H.B.; Supervision - K.G.; Resource - A.A.; Materials - A.A.; Literature Search S.Ş, Ş.Ö.; Writing - K.G., H.B.; Critical Reviews - K.G., H.B., A.A.

Conflict of Interest: No conflict of interest was declared by the authors.

Financial Disclosure: The authors declared that this study has received no financial support.

\section{REFERENCES}

1. Kaner T, Sasani M, Oktenoglu T, Solmaz B, Sarloglu AC, Ozer AF. Clinical analysis of 21 cases of spinal cord ependymoma: positive clinical results of gross total resection. J Korean Neurosurg Soc 2010;47:102-6. [CrossRef]

2. Wang H, Zhang S, Rehman SK, Zhang Z, Li W, Makki MS, et al. Clinicopathological features of myxopapillary ependymoma. J Clin Neurosci 2014;21:569-73. [CrossRef]

3. Duggan MA, Hugh J, Nation JG, Robertson DI, Stuart GC. Ependymoma of the uterosacral ligament. Cancer 1989;64:2565-71. [CrossRef]

4. Fujimori T, Iwasaki M, Nagamoto Y, Kashii M, Sakaura H, Yoshikawa $\mathrm{H}$. Extraneural metastasis of ependymoma in the cauda equina. Global Spine J 2013;3:33-40.

5. Mavroudis C, Townsend JJ, Wilson CB. A metastasizing ependymoma of the cauda equina. Case report. $J$ Neurosurg 1977;47:771-5. [CrossRef]

6. Louis DN, Ohgaki H, Wiestler OD, Cavenee WK, Burger PC, Jouvet A, et al. The $2007 \mathrm{WHO}$ classification of tumours of the central nervous system. Acta Neuropathol 2007;114:97-109. [CrossRef]

7. Rickert CH, Kedziora O, Gullotta F. Ependymoma of the cauda equina. Acta Neurochir (Wien) 1999;141:781-2. [CrossRef]

8. Suri VS, Tatke M, Singh D, Sharma A. Histological spectrum of ependymomas and correlation of p53 and Ki-67 expression with ependymoma grade and subtype. Indian J Cancer 2004;41:66-71.

9. Ruda R, Gilbert M, Soffietti R. Ependymomas of the adult: molecular biology and treatment. Curr Opin Neurol 2008;21:754-61. [CrossRef]

10. Hirahara F, Yamanaka M, Miyagia E, Nakazawa T, Gorai I, Minaguchi $\mathrm{H}$, et al. Pure ovarian ependymoma: report of a case treated with surgery, chemotherapy, irradiation and hyperthermotherapy. Eur J Obstet Gynecol Reprod Biol 1997;75:221-3. [CrossRef] 